\title{
Green ceramic pigment based on chromium recovered from a plating waste
}

\author{
Griselda X. Gayo*, Araceli E. Lavat \\ CIFICEN (CONICET-UNCPBA-CICPBA), Facultad de Ingeniería, Universidad Nacional del Centro de la Provincia de Buenos Aires, Av. Del Valle 5737, B7400JWI \\ Olavarría, Argentina
}

A R T I C L E I N F O

\section{Keywords:}

Chrome plating waste

$\mathrm{Cr}_{2} \mathrm{O}_{3}$ recovery

Characterization

Ceramic pigments

Glazes

Solidification/Stabilization

\begin{abstract}
A B S T R A C T
The development of pigments with new formulas, departing from lower-cost raw materials, is driven by market growth and competitiveness required by the ceramic sector. In this work, the application of a residue from a metallurgical plant, containing a high amount of chromium (III) in ceramics glazes was studied. $\mathrm{Cr}_{2} \mathrm{O}_{3}$ was successfully separated from chrome plating waste resulting in a suitable synthesize ceramic pigment, based on this chromophore. A washing treatment was applied to the residue followed by a calcination at $1000{ }^{\circ} \mathrm{C}$ prior to the usage as pigment. The adequate purity of $\mathrm{Cr}_{2} \mathrm{O}_{3}$ recovered from waste was confirmed by analytical techniques (XRF, XRD, DTA-TG, FTIR and SEM-EDX). The glasses, containing $5 \mathrm{wt} \%$ of recovered $\mathrm{Cr}_{2} \mathrm{O}_{3}$, were carried out using frits and transparent micronized glass for mono- and double firing processes. The materials were characterized by XRD and FTIR, and by the colorimetric parameters CIELab. The resulting glazes containing the waste are within the range of typical pigments based on $\mathrm{Cr}_{2} \mathrm{O}_{3}$ in silicate and aluminate glazes for single firing, showing dark green hues in comparison with the previous data obtained from commercial grade $\mathrm{Cr}$ (III) oxide. However the presence of small amounts of the other chromophores in the waste modifies the tonality, affecting the purity of the chroma by increasing darkness. The leaching tests performed on the glazes suggest that $\mathrm{Cr}$ (III) is stable in this ceramic matrix. This results show that glazing is a suitable process for the Solidification/ Stabilization of this waste.
\end{abstract}

\section{Introduction}

Currently, one of the main requisites for sustainable industrial development is appropriate waste management. Therefore recycling and adding commercial value to end products have emerged as interesting strategies for many industries. The re-utilization of waste contributes, at the same time, to reduce final costs by replacing other raw materials, and the cost of disposal and environmental impact.

New products made out of recycled waste materials mainly involve the transformation of the waste into cementitious agglomerates, ceramics, glass and glass-ceramic. Among these, ordinary Portland Cement (OPC) provides an adequate matrix to immobilize many hazardous residues in a very easy way before its landfill deposit. However the durability of cement-based waste mixtures is still under discussion and the products cannot be used in the building industry. In this way, technological recovery procedures involving ceramic and glass seem to be more suitable for inertization of hazardous wastes because these are stable matrices with important volume reduction [1].

Some industries consume high amounts of raw materials and are able to receive waste which can then be reconverted. The construction and building industry is an example of this, since a large amount of construction products are produced worldwide. A variety of waste materials, including construction rubble, tile rubber ash, blast furnace slag, silica fume, fly ash, and biological limestone have been successfully added in mortars, reducing the amount of Portland cement needed. The use of granite sludge wastes for the production of colored cement-based mortars has been previously investigated [2]. Moreover, ceramic waste tiles as a pozzolanic addition, have been reported elsewhere [3].

Some toxic elements which are dangerous for the health and the environment could be immobilized in vitreous matrix. In the case of glass ceramics the leaching tests performed demonstrated that the vitrified toxic elements are well stabilized in the formed phases [4].

Metallurgy in general, chrome plating and galvanizing or surface coating processes, generates large amounts of sludge, rich in metals such as $\mathrm{Cr}$ or $\mathrm{Ni}$, which can be used in the formulation of ceramic pigments and other colored ceramic products. The production of green Ni-olivine pigment from such waste has been previously reported [5]. Heavy metals such as $\mathrm{Cu}, \mathrm{Zn}, \mathrm{Pb}$ and Co could be recovered from the large amount of copper slag production, as a benefit of sulfur mines. Brown and black pigments, which are in high demand by the ceramic industry, have been produced from copper slag [6]. Black ceramic

\footnotetext{
* Corresponding author.

E-mail address: xgayo@fio.unicen.edu.ar (G.X. Gayo).
} 
pigments have been prepared using industrial wastes from $\mathrm{Cr} / \mathrm{Ni}$ plating and Fe- based on the $\mathrm{Cr}-\mathrm{Fe}-\mathrm{Ni}$ black spinel $(\mathrm{Ni}, \mathrm{Fe})(\mathrm{Fe}, \mathrm{Cr})_{2} \mathrm{O}_{4}$ (13-50-9 DCMA classification) [7]. The recycling of Zn-hydrometallurgy in glass and glass-ceramic have been reported as being suitable for building products, such as tiles, glass fibers, and pigments for ceramics [1].

Fe-Mn wastes from the electrolytic production of $\mathrm{MnO}_{2}$ were used in the manufacture of colored ceramic building products (e.g., bricks, tiles, etc.), ranging from light to dark green [8].

Other metals have been recovered from waste material. An important example is the production of $\mathrm{Zn}$ and oxide particles by pyrolysis of alkaline and $\mathrm{Zn}-\mathrm{C}$ battery waste. Considering that battery waste generation has been increased worldwide, the huge amount of discarded batteries requires management. Normally, the waste management is regulated by complicated local and/or national laws and legislation. Submicron $\mathrm{Zn}$ particles can be used as catalyst, electrode material, or anticorrosive pigment. Recovered $\mathrm{MnO}$ particles have applications as a pigment or electrode material [9].

Cr-doped materials have been largely investigated as ceramic pigment. A wide variety of hues tonalities and colors are possible by $\mathrm{Cr}$ chromophore. However $\mathrm{Cr}$, such as other transition metals can adversely affect the environment and human health. Despite this facts, $\mathrm{Cr}$ (III) is an essential element with an insulin mimetic biological role; however, in higher doses it becomes toxic since it affects the body's immune system. $\mathrm{Cr}(\mathrm{VI})$ is even more toxic because it enters into cells and is carcinogenic. In addition, the oxidation of $\mathrm{Cr}(\mathrm{III})$ to $\mathrm{Cr}(\mathrm{VI})$ should be prevented because of its negative impact on the environment, since it is more soluble and will be segregated to the washing waters [10].

One of the earliest reports regarding the application of $\mathrm{Cr}$ - containing pigments recovered from waste proposes the preparation of Co$\mathrm{Cr}$ green and $\mathrm{Cr}-\mathrm{Sn}$ pink pigments from leather shavings produced as a waste product from the tanning industry [11]. Later, the preparation of other typical Cr-pigments using Al-rich sludge generated in an anodizing wastewater treatment unit from an industrial plant was also reported [12].

In the following paper, we present the application of a residue proceeding from a metallurgical plant, containing high amount of chromium (III), in ceramic glazes. The waste is studied thoroughly in order to design an optimization process prior to its technical use, and later incorporated in vitreous matrices as ceramic pigment. The potential environmental risks are also evaluated.

\section{Experimental part}

\subsection{Recovery of $\mathrm{Cr}_{2} \mathrm{O}_{3}$ from waste}

The industrial waste was collected and analyzed prior to be used as $\mathrm{Cr}_{2} \mathrm{O}_{3}$. The received residue (AR) consists of a powdered mixture of white and green particles. An $18 \%$ weight loss attributed to humidity was measured after drying for a few hours at $110^{\circ} \mathrm{C}$ and a constant weight was achieved. With the aim to eliminate volatile and organic compounds present in the residue, two calcinations steps were carried out at $550{ }^{\circ} \mathrm{C}$ and $1000{ }^{\circ} \mathrm{C}$. Mass losses of $41.37 \%$ and $46.82 \%$, respectively, were determined. As detailed in Table 1, according to XRF technique, the main components of AR material expressed in oxides are $\mathrm{SO}_{3}, \mathrm{Na}_{2} \mathrm{O}$ and $\mathrm{Cr}_{2} \mathrm{O}_{3}$, representing around $90 \mathrm{wt} \%$.

In view of these results, separation procedures were designed in the laboratory in order to get recovered $\mathrm{Cr}_{2} \mathrm{O}_{3}$ from the residue as pure as possible. The optimized residue was labeled OR.

The AR was washed with deionized water at ambient temperature, and stirred to favor the dissolution of salts. Later, it was filtered through a Whatman filter paper to separate the Cr-containing solid (WR). The procedure was repeated three times. Next, the slightly acid solution $(\mathrm{pH}=6)$ was evaporated and the recovered crystals $(\mathrm{RC})$ were analyzed by XRD and FTIR. Finally, in order to obtain OR, the dry solid residue (WR) was calcined in a muffle electrical furnace for $3 \mathrm{~h}$ at
Table 1

Chemical composition of $\mathrm{Cr}$ waste as received (AR), and optimized Cr residue (OR), in oxides (wt \%).

\begin{tabular}{lll}
\hline Oxides & AR (wt\%) & OR (wt \%) \\
\hline $\mathrm{SO}_{3}$ & 35.62 & - \\
$\mathrm{Na}_{2} \mathrm{O}$ & 25.49 & - \\
$\mathrm{Cr}_{2} \mathrm{O}_{3}$ & 24.10 & 65.42 \\
$\mathrm{Al}_{2} \mathrm{O}_{3}$ & 5.32 & 18.25 \\
$\mathrm{CaO}$ & 2.82 & 2.88 \\
$\mathrm{PbO}$ & 1.52 & 2.00 \\
$\mathrm{CuO}$ & 1.47 & 3.96 \\
$\mathrm{Fe}$ & 1.20 & 3.42 \\
$\mathrm{Cl}$ & 1.04 & - \\
$\mathrm{P}_{2} \mathrm{O}_{5}$ & 0.70 & - \\
$\mathrm{SiO}$ & 0.67 & 3.13 \\
$\mathrm{ZnO}$ & 0.05 & 0.14 \\
$\mathrm{SnO}$ & - & 0.39 \\
$\mathrm{MgO}$ & - & 0.30 \\
$\mathrm{I}$ & - & 0.09 \\
$\mathrm{SrO}$ & - & 0.01 \\
\hline
\end{tabular}

Table 2

EDX elemental composition of OR.

\begin{tabular}{lllllllll}
\hline Elements & C & O & Al & Si & Ca & Cr & Fe & Cu \\
\hline Weight \% & 16.13 & 29.56 & 6.42 & 0.53 & 1.17 & 41.05 & 1.83 & 3.32 \\
Elements \% & 30.86 & 42.47 & 5.46 & 0.43 & 0.67 & 18.15 & 0.75 & 1.20 \\
\hline
\end{tabular}

$1000^{\circ} \mathrm{C}$. The chemical composition of OR was also determined by XRF analysis (Table 1). In addition, the material was characterized by SEM, and the EDX elemental composition, as can be seen in Table 2.

\subsection{Characterization of materials}

The X-ray fluorescence analysis (XRF) of the materials was carried out by an energy dispersive spectrometer, Shimadzu, model EDX$800 \mathrm{HS}$.

The thermal evolution of the washed residue (WR) was studied using a RIGAKU differential thermal analyzer, Thermo Plus Evo series, which has a differential TG-ATD horizontal high-temperature module. The tests were carried out in $100 \mathrm{ml} / \mathrm{min}$ air flow, with alumina as reference; using platinum crucibles and a heating rate of $10^{\circ} \mathrm{C} / \mathrm{min}$, up to $1150^{\circ} \mathrm{C}$.

The materials were studied by $\mathrm{x}$-ray diffraction (XRD) and Fourier Transformed Infrared Spectroscopy (FTIR). X-ray diffraction patterns were obtained using a Philips PW 3710 diffractometer equipped with graphite monochromator, using CuKa radiation, operating at $40 \mathrm{kV}$ and $20 \mathrm{~mA}$. The following x-ray data collection details were applied: step interval: $0.02^{\circ}$ and step time: 0.5 (s). Unit cell parameters were obtained using a least-square procedure and refined with a locally modified version of the Werner PIRUM program [13]. The XRD measurements were calibrated using $\mathrm{Si}$ as the internal standard.

The infrared spectra were recorded on a Nicolet-Magna 550 FT-IR instrument, using the $\mathrm{KBr}$ pellet technique. The measurements were carried out in the $4000-250 \mathrm{~cm}^{-1}$ region.

The microstructure of the OR, on superficially polished gold-coated specimens, was obtained by a scanning electron microscopy (SEM) (Carl Zeiss, model MA10). The x-ray dispersive microanalysis was performed with EDS Orford equipment, model INCA energy.

The pigmenting aptitude of the optimized material, incorporated in glazes, was evaluated. For this purpose, suspensions of pigments with frits were prepared. The approximate composition of the transparent frits employed is detailed in Table 3. These glazes are representative of the double and single firing processes, currently applied in roof and floor tiles manufacturing.

Prior to enameling the pigment and ceramic frit test, specimens 
Table 3

Composition of ceramic frits, in oxides, wt $\%$.

\begin{tabular}{llll}
\hline Oxides & Frit A (wt\%) & Frit C (wt\%) & MD (wt\%) \\
\hline $\mathrm{Na}_{2} \mathrm{O}$ & 3 & 6 & 4.5 \\
$\mathrm{~K}_{2} \mathrm{O}$ & 2 & 2 & 4.5 \\
$\mathrm{CaO}$ & 4 & 4 & 5 \\
$\mathrm{MgO}$ & - & - & 5 \\
$\mathrm{PbO}$ & 30 & - & - \\
$\mathrm{B}_{2} \mathrm{O}_{3}$ & 5 & 16 & 8 \\
$\mathrm{Al}_{2} \mathrm{O}_{3}$ & 6 & 10 & 8 \\
$\mathrm{SiO}_{2}$ & 50 & 62 & 65 \\
\hline
\end{tabular}

were prepared by thoroughly mixing. The mixtures were homogenized in an agate mortar with $5 \mathrm{wt} \%$ of powdered $\mathrm{Cr}_{2} \mathrm{O}_{3}$-OR. For comparison purposes, chromium oxide $\mathrm{Cr}_{2} \mathrm{O}_{3}$ (BDH $99 \mathrm{wt} \%$ ) was used for all the preparations. Every batch was wet mixed and the slip was spread on porous ceramic tiles, then dried in air and finally subjected to thermal treatment. In some cases, particularly for leaching tests, cylindrical test specimens were formed by pressing the wet powder at $416 \mathrm{MPa}$. The resulting pellets were put onto ceramic biscuits and fired. The thermal cycles consisted in heating up to $1000^{\circ} \mathrm{C}$ at $25^{\circ} \mathrm{C} / \mathrm{min}$, holding this temperature for $15 \mathrm{~min}$. A further step was made at $573^{\circ} \mathrm{C}$, holding for $30 \mathrm{~min}$. The pure frit was also fired at different temperatures for comparative purposes. All the samples were milled and characterized by XRD and FTIR.

The technological performance of the glazes was evaluated through measuring the colorimetric behavior. CIE $L^{*} a * b *$ color coordinates of coated tiles were obtained with a Braive Super Chroma $20 \mathrm{~mm}$ colorimeter and a white standard as reference. The chroma $c^{*}$ and the tone $h^{*}$ were calculated by means of the following equations. $C^{*}=\left(a^{*^{2}}+\right.$ $\left.b^{* 2}\right)^{1 / 2}$ and $h^{*}=\arctan \left(b * / a^{*}\right)$. The color difference $\Delta E^{*}$ between two samples was calculated as the Euclidean distance between each color stimulus in the CIELAB space. Where $\Delta E^{*}=\left(\Delta L^{*^{2}}+\Delta a^{* 2}+\Delta b^{*^{2}}\right)^{1 / 2}$ (ISO 10545-16:1999).

\subsection{Leaching tests}

The efficiency of the solidification/stabilization process was examined by the leaching behavior of the glazes. To get a deeper insight about the leachate from glazes containing recovered $\mathrm{Cr}_{2} \mathrm{O}_{3}$, cylindrical test specimens, containing the powdered mixtures of frit $\mathrm{C}$ and $5 \mathrm{wt} \%$ $\mathrm{Cr}_{2} \mathrm{O}_{3}$-OR were formed and calcined to $1000{ }^{\circ} \mathrm{C}$, as mentioned in the previous section.

The standard leaching test refers to a liquid/dry solid ratio with enough water to completely cover the solid, simulating conditions in landfill [14]. The samples were crushed and milled to a particle size of about or below $9.5 \mathrm{~mm}$. The procedure consist of leaching by dispersing a fixed mass of dry solid with deionized water and shaking during $24 \mathrm{hs}$, at a constant temperature of $25^{\circ} \mathrm{C}$. The necessary volume of acetic acid $0.5 \mathrm{~N}$ was added to maintain the $\mathrm{pH}$ of the solution stable at $5 \pm 0.2$. The $\mathrm{pH}$ was controlled by a $\mathrm{pH}$ meter. Afterwards, elute was filtered and centrifuged to avoid the presence of fine particles and collected into flasks. The test was duplicated to validate the results.

Later, samples were taken for $\mathrm{Cr}(\mathrm{VI})$-determination. Hexavalent chromium was measured according to the standard procedure formulated by NORM IRAM [15]. The Cr(VI) reacts quantitatively with the 1,5-diphenylcarbazide to form 1,5-diphenylcarbazone, which gives a red complex (0.01-0.50 mg/chrome). Then $\mathrm{Cr}(\mathrm{VI})$ was determined by colorimetric analysis. For this purpose, $25 \mathrm{ml}$ of the sample is poured into a $50-\mathrm{ml}$ Erlenmeyer flask, adding $2 \mathrm{ml}$ of the diphenylcarbazide solution $(0.25 \mathrm{~g}$ of diphenylcarbazide in a $50 \mathrm{ml}$ solution of acetone and $50 \mathrm{ml}$ of water) as reagent. The samples were introduced into a spectrophotometer at $540 \mathrm{~nm}$. The calibration plot was obtained using a standard solution of chromium.

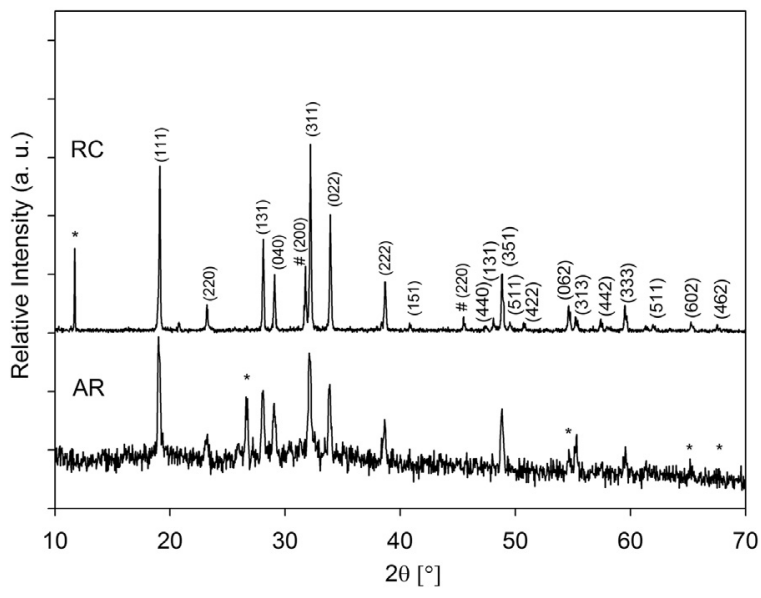

Fig. 1. XRD patterns of industrial residue AR, and of crystals recovered after washing $\mathrm{RC}\left(\mathrm{Na}_{2} \mathrm{SO}_{4}\right.$-Thenardite, (\#) $\mathrm{NaCl}$ and $\left(^{*}\right)$ unidentified impurity.

\section{Results and discussion}

The industrial residue was subjected to washing and drying treatments, followed by calcination up to $1000^{\circ} \mathrm{C}$ prior to use, as described previously. Subsequently, the colorimetric properties of the glazes were evaluated after the incorporation of the pigment and subjected to thermal treatment.

\subsection{Characterization of waste AR and application as pigment}

In order to obtain a pigment for glazing, with certain composition, it is necessary to determine the chemical composition of the residue prior to its incorporation in the formulation of pigments.

Usually Cr-plating sludge is mainly composed of water and soluble salts; accompanied by metallic species and processing additives that depends on the liquid effluents treatment applied. In general, the process involves a precipitation stage, starting with a reduction of $\mathrm{Cr}(\mathrm{VI})$ to (III), in acid media, by adding a reductant, such as $\mathrm{HNaSO}_{3}$, followed by neutralization and coagulation-flocculation [16].

The comparison of the AR and RC XRD patterns shown in Fig. 1, suggest that the major soluble salts, accompanying the $\mathrm{Cr}$ - residue, are efficiently extracted by waste washing. The recovered crystalline solid (RC) was undoubtedly identified mainly as $\mathrm{Na}_{2} \mathrm{SO}_{4}$-thenardite and a secondary component of $\mathrm{NaCl}$-halite. All the diagnostic peaks of the reference mineral are present, as can be concluded from Fig. 1.

The identification was confirmed by FTIR analysis. As can be seen in Fig. 2 the main bands observed in the spectrum are associated to the $\mathrm{SO}_{4}=$ group, constituent of the mineral thenardite. The spectra of the samples labeled AR and RC are identical. The two typical bands

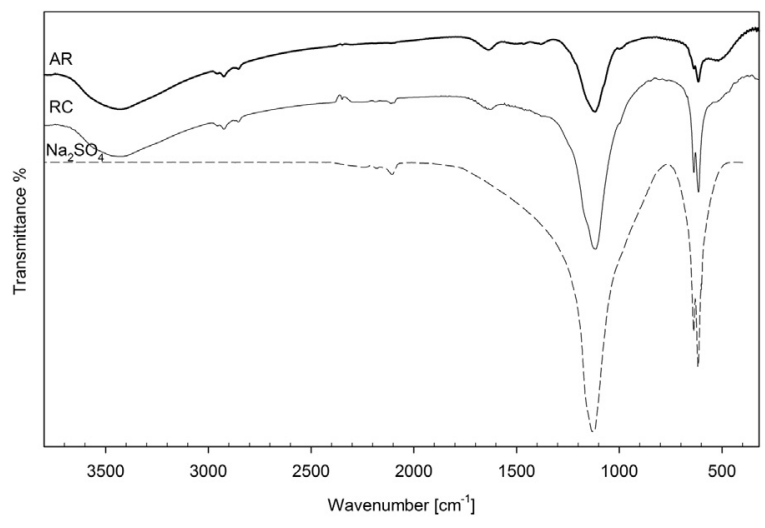

Fig. 2. FTIR spectra of $\mathrm{AR}, \mathrm{RC}$ and $\mathrm{Na}_{2} \mathrm{SO}_{4}$-thenardite. 
assigned to $\nu_{3}$ antisymmetric stretching of S-O bonds and $\nu_{4}$ deformations of O-S-O angles are observed at 1123 and $615 \mathrm{~cm}^{-1}$, respectively, in total accordance with the reference spectrum of this mineral, available in the spectral library [17]. The presence of $\mathrm{NaCl}$, detected by $\mathrm{XRD}$, was not possible to confirm because this solid is transparent to IR radiation and therefore remains undetectable.

The other minor signals (in the high energy region of the IR spectrum), as the broad band lying at $3550-2000 \mathrm{~cm}^{-1}$ and at $1600 \mathrm{~cm}^{-1}$, are due to $\mathrm{OH}-$ stretching and $\mathrm{H}-\mathrm{O}-\mathrm{H}$ deformation vibrations, respectively. These signals are attributed to the hydroxyl groups of the hydrated oxide surface and adsorbed water, which are highly sensitive to IR radiation [18].

In addition, other spurious signals observed in the range $2900-2800 \mathrm{~cm}^{-1}$, are attributed to stretching motions of C-H aliphatic bonds and at $2100 \mathrm{~cm}^{-1}$ assignable to other functional group frequencies, present in organic compounds, from the additives used for $\mathrm{Cr}$ plating, during manufacturing.

These results are compatible with the chemical composition, expressed in oxides, determined by XRF, and detailed in Table 1 .

\subsubsection{Characterization of recovered $\mathrm{Cr}_{2} \mathrm{O}_{3}-\mathrm{OR}$}

The optimized Cr-residue (OR) was characterized by DTA-TG thermal measurements, XRD, FTIR spectroscopy and SEM-EDX analysis, prior to being used in replacement of $\mathrm{Cr}_{2} \mathrm{O}_{3}$, in enamels.

The XRD pattern of the product obtained after washing and drying (WR) is shapeless, suggesting that it is amorphous (Fig. 3). When this sample is subjected to calcination from $100^{\circ}$ to $1000^{\circ} \mathrm{C}$, in order to render the $\mathrm{OR}$, the typical diffraction lines from crystalline $\mathrm{Cr}_{2} \mathrm{O}_{3}$ (JCPDF\#381479) appear, as shown in the same figure [19].

The thermogram of non-crystalline WR was registered in order to study its thermal behavior and to interpret the changes that occurred during calcinations up to $1000^{\circ} \mathrm{C}$. The TG and DTA curves, shown in Fig. 4, are rather simple. Analyzing the TG curve, two thermal steps separated by the sharp signals around $300{ }^{\circ} \mathrm{C}$ appear. A continuous weight loss of $38.96 \%$, is observed in the thermal range from ambient to $100{ }^{\circ} \mathrm{C}$, followed by a drastic mass loss at $330^{\circ} \mathrm{C}$. It can be assigned to dehydration and relief of gases from thermal decomposition of organic matter, in presence of air in almost a single step. From $330-1000{ }^{\circ} \mathrm{C}$ a very slight weight loss is registered and no other thermal effects are observed, since the TG curve is almost featureless in this thermal interval. According to previous studies, the sharp exothermic signal at $330^{\circ} \mathrm{C}$ has been interpreted to the crystallization of $\mathrm{Cr}_{2} \mathrm{O}_{3}$ from an amorphous phase departing from some precursor synthetic routes [20]. The mass loss seems to correspond mainly to the decomposition of the hydrated oxides forming $\mathrm{Cr}_{2} \mathrm{O}_{3}$ as the main component, followed by its crystallization. This thermal stage is accompanied by the release of light molecules, mainly $\mathrm{H}_{2} \mathrm{O}$ and other volatile minor components, as

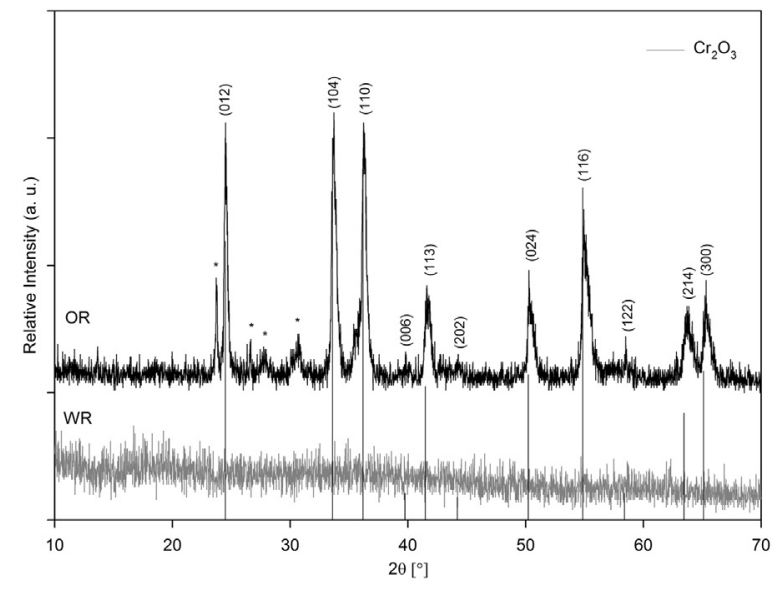

Fig. 3. XRD patterns of WR, OR and $\mathrm{Cr}_{2} \mathrm{O}_{3}$-eskolaite. (*) unidentified impurity.

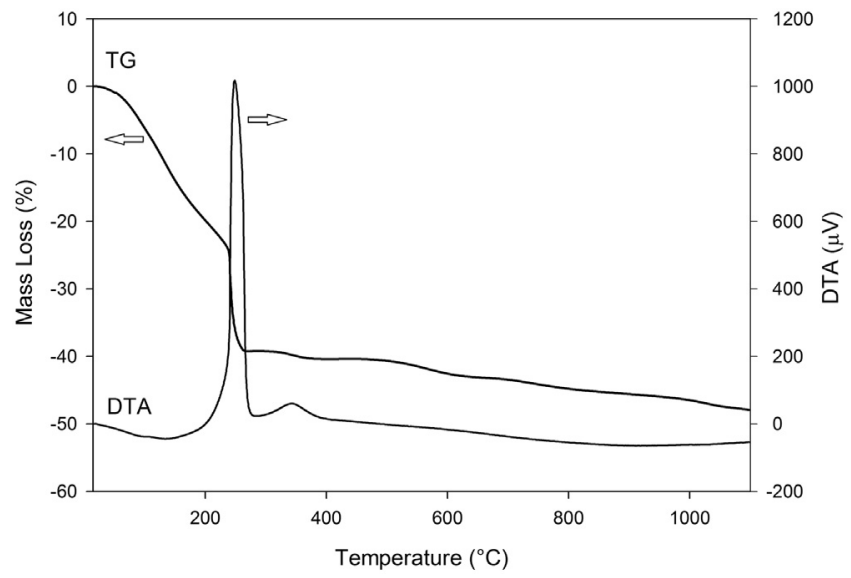

Fig. 4. TG-DTA curves of WR.

products of the destruction of the residual organic matter.

As will be shown below, the thermogravimetric assignment was confirmed by XRD and FTIR measurements. In accordance with previous reports [20], the crystallization was supported by the unambiguous change of the XRD pattern for the samples quenched before and after the sharp exothermic peak. The crystallinity of the sample calcined at $500{ }^{\circ} \mathrm{C}$ could be enhanced upon firing up to $1000^{\circ} \mathrm{C}$. As can be seen in Fig. 3, the XRD pattern displays the diffraction lines belonging to $\mathrm{Cr}_{2} \mathrm{O}_{3}$-eskolaite. The diffractogram could be indexed based on the corundum hexagonal structure, space group $R-3 C$. The unit cell parameters calculated are $\mathrm{a}=\mathrm{b}=4.95(2) \AA$ and $\mathrm{c}=13.58(1) \AA$. These values are in good agreement with the reported values [19].

The structural characterization described is compatible with the chemical composition of OR, determined by XRF analysis. According to the data shown in Table 1, the solid consists mainly of $\sim 65 \mathrm{wt} \% \mathrm{Cr}_{2} \mathrm{O}_{3}$ and also includes $\sim 18 \mathrm{wt} \% \mathrm{Al}_{2} \mathrm{O}_{3}$. Due to the similarity in ionic radii between $\mathrm{Cr}(\mathrm{III})$ and $\mathrm{Al}(\mathrm{III})$, the oxides are isostructural, and the cells should have similar sizes, undistinguishable by their XRD patterns [21]. Moreover, the possibility of forming a solid solution between them should not be disregarded. Regarding the other oxides, present as minor components according to XRF data, these are not observed by XRD likely because these are under the detection limits. The potential presence of the spinel $\mathrm{CuFe}_{2} \mathrm{O}_{4}$, the product of reaction between $\mathrm{Cu}(\mathrm{II})$ and Fe(III), should not be disregarded.

The infrared spectra give additional support to DTA-TG, XRD and XRF results. FTIR spectroscopic characterization is a very useful tool to evaluate the chemical and structural changes during the processing of the AR sample, with the advantage that even poorly crystallized and amorphous compounds can be identified.

The IR spectral measurements of the samples, carried out after each treatment, are depicted in Fig. 5. The evolution of the IR spectra show predominance of $\mathrm{SO}_{4}=$ bands at $1200 \mathrm{~cm}^{-1}$ and $600 \mathrm{~cm}^{-1}$ in AR, with remarkable diminution after washing in WR sample until disappearance. In addition, a new absorption is developed in the low energy IR region; a broad poorly defined band centered at $\sim 600 \mathrm{~cm}^{-1}$. When the material is submitted to thermal treatment in order to achieve the OR, a drastic change in the spectral features is detected. Two well defined doublets with strong absorptions at $635-577 \mathrm{~cm}^{-1}$ and other weaker and less defined bands covering $400-360 \mathrm{~cm}^{-1}$ can be observed. As can be seen in Fig. 5, this spectral pattern is identical to the spectrum of $\mathrm{Cr}_{2} \mathrm{O}_{3}$ p.a., shown in the literature and the spectral libraries [17]. The doublet located at the higher wavenumber is assigned to the stretching vibration of $\mathrm{Cr}-\mathrm{O}$ bonds in the $\mathrm{CrO}_{6}$ condensed octahedrons forming the lattice of $\mathrm{Cr}_{2} \mathrm{O}_{3}$-eskolaite, and the lower energy bands belong to deformational modes of the same polyhedron [19]. On the other hand, the spurious broad shapeless band at around $1000 \mathrm{~cm}^{-1}$ is difficult to assign unambiguously and could be attributed to $\mathrm{M}-\mathrm{OH}$ 


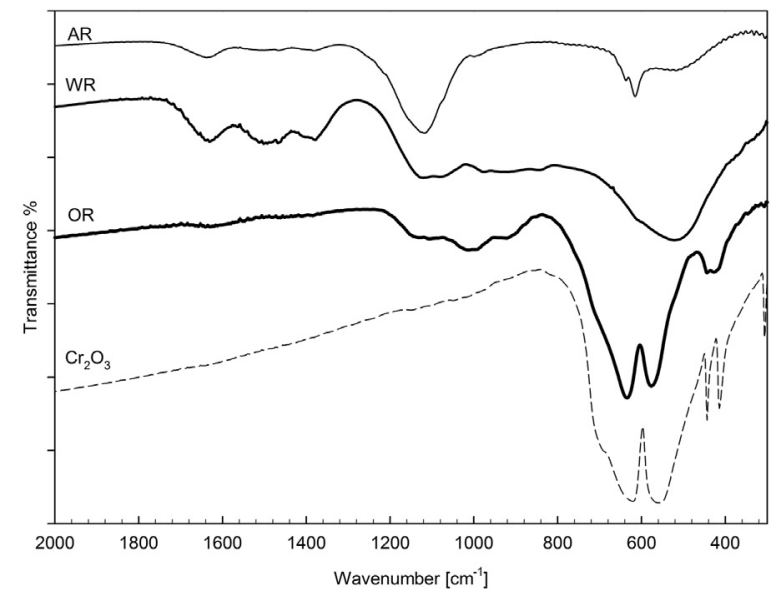

Fig. 5. FTIR spectra of $\mathrm{AR}, \mathrm{WR}, \mathrm{OR}$ and $\mathrm{Cr}_{2} \mathrm{O}_{3}$.

stretching vibrations of the remaining impurities in the sample [18].

The SEM images of the OR, with different degrees of magnification, are illustrated in Fig. 6. The sample depicts homogeneous microstructure. The magnified pictures, shown in Figs. $6 \mathrm{a}, 6 \mathrm{~b}$ and $6 \mathrm{c}$, distinguish small micro particles of $\mathrm{Cr}_{2} \mathrm{O}_{3}(<<2 \mu \mathrm{m})$ forming agglomerates of bigger sizes.

Moreover, the EDX scanning confirmed that the global elemental composition detailed in Table 2 is compatible with the presence of $\mathrm{Cr}_{2} \mathrm{O}_{3}$, as the main component, in consistence with XRF quantitative analysis and previously used techniques. A significant amount of $\mathrm{C}$, which appear as ashes after calcinations, was also detected which could be associated with carbonaceous residues departing from oils or other organic compounds used during the machinating of the pieces. The presence of the other elements, $\mathrm{Al}, \mathrm{Fe}$ and $\mathrm{Cu}$, is not surprising since these are components of the alloys commonly used in the industry.

In summary the simple optimization process applied to render OR, according to the analytical techniques XRF, XRD, DTA-TG, FTIR and

a

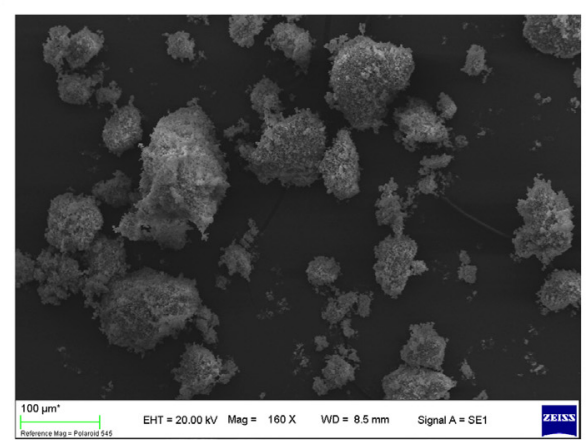

SEM-EDX, seems to be appropriate in order to achieve $\mathrm{Cr}_{2} \mathrm{O}_{3}$ recovered from the residue of acceptable purity for the synthesis of pigments. Chromium oxide is accompanied by $\mathrm{Al}_{2} \mathrm{O}_{3}$ and other minor impurities, compatible with the composition of (white) ceramic raw materials. The effect of the presence of other chromospheres, such as $\mathrm{Cu}$ and $\mathrm{Fe}$, as probably the mixed oxide $\mathrm{CuFe}_{2} \mathrm{O}_{4}$, was analyzed.

\subsubsection{Frits characterization}

The frits, forming transparent coatings, were provided by a local ceramic industry which manufactures floor and roof tiles. The approximate compositions are detailed in Table 3 . The glazes were selected to be representative of the double and single firing procedures. In the case of frit A (FA), the high amount of PbO applies for a low softening point, commonly used in overglaze applications, carried out at around $850^{\circ} \mathrm{C}$ in the so-called double firing processes. Frits $\mathrm{C}(\mathrm{FC})$ and micronized glaze (MD) both could be used in single firing schedules due to the higher softening and glazing temperatures, $1000^{\circ} \mathrm{C}$ and $1100{ }^{\circ} \mathrm{C}$, respectively. $\mathrm{MD}$ was received as micronized powder containing particles $<<44 \mu \mathrm{m}$. Both frits A and C consist of flakes which were crushed and then submitted to grinding using a laboratory ball mill. The resulting powders were sieved through a $44 \mu \mathrm{m}$ sieve (325 mesh).

The common feature of all frits is the absence of $\mathrm{ZnO}$, which could react with Cr-pigments. In addition, frits $\mathrm{C}$ and $\mathrm{MD}$ contain a high amount of $\mathrm{SiO}_{2}$, higher in $\mathrm{MD}$, compatible with a higher melting point. In the case of frit $C$, it bears a significant amount of $\mathrm{B}_{2} \mathrm{O}_{3}$ as glass former; and also $\mathrm{Al}_{2} \mathrm{O}_{3}$.

The XRD patterns of all the frits are featureless due to their amorphousness, so the chemical characterization relies on the spectroscopic behavior, analyzed by FTIR vibrational spectroscopy. As can be seen from Fig. 7, the spectral patterns of FA and MD (and also FC) have been assigned in previous papers; the differences can be explained based on the chemical composition among the frits. In FA, only bands belonging to $\mathrm{SiO}_{2}$, located in the $1070-1010 \mathrm{~cm}^{-1}$ and around $475-400 \mathrm{~cm}^{-1}$, are present. These vibrations are typical of $\mathrm{SiO}_{4}{ }^{3-}$, belonging to stretching and deformational motions of tetrahedral units, respectively. In the case of FC and MD, besides these silicate spectral signals, the vibrations

b

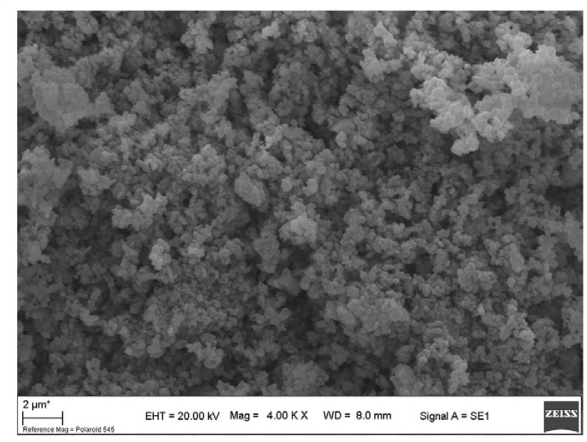

C

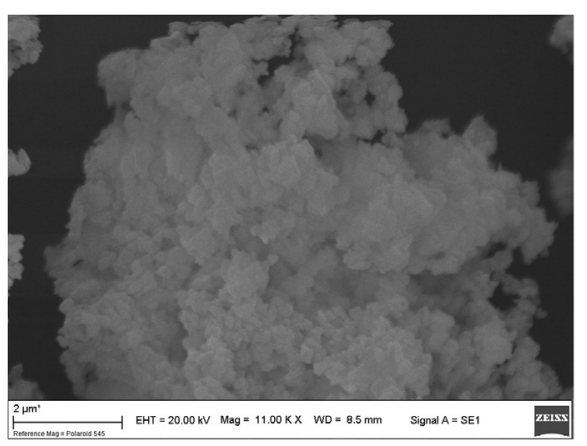

Fig. 6. SEM micrograph of OR, a) $160 \times$, b) $4.00 \mathrm{KX}$ and c) $11.00 \mathrm{KX}$. 


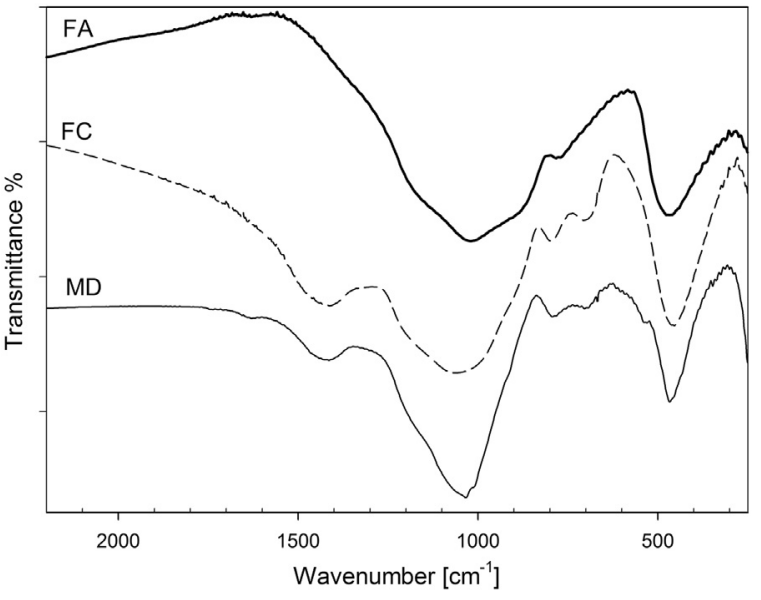

Fig. 7. FTIR plots of frits A and MD.

arising from $\mathrm{B}_{2} \mathrm{O}_{3}$ assigned to the extra bands at $1400 \mathrm{~cm}^{-1}$ and $700 \mathrm{~cm}^{-1}$, are observed [22].

\subsubsection{Technological properties of glazes based on recovered $\mathrm{Cr}_{2} \mathrm{O}_{3}-\mathrm{OR}$}

Historically, in the ceramic industry, green pigmentation has been obtained with $\mathrm{Cr}_{2} \mathrm{O}_{3}$. This material is an important refractory with a high melting point $\left(2435^{\circ} \mathrm{C}\right)$. However the presence of $\mathrm{ZnO}$ or $\mathrm{SnO}_{2}$, usually present as opacifiers in opaque frits, produces a deleterious effect on color stability because of the mutual reaction [23]. For this reason $\mathrm{Cr}_{2} \mathrm{O}_{3}$-OR recovered from the waste was submitted to testing by glazing with the three transparent frits, previously described. The colorimetric parameter measurements were made on white ceramic glaze tiles, at the stated temperatures of glazing of each frit.

The resulting CIEL ${ }^{*} a * b *$ coordinates of all the specimens, including the starting powders, are detailed in Table 4 . The colorimetric parameters of glazes based on pure $\mathrm{Cr}_{2} \mathrm{O}_{3}$ are also included for comparison. As shown in the table, the colorizing behavior of the pigments prepared from the waste are within the range of the reference pigment in all the glazes investigated, in the same region of the chroma diagram. The color differences, evaluated by $\Delta E^{*}$, the chroma $c^{*}$ and the tone $h^{*}$ can be seen in Table 4 .

According to the data in Table 4, the maintenance of the green hue is dependent on the frit and thermal treatment. The coloring level of the starting powders is maintained when they are enameled with transparent frits. The negative value $-a^{*}$, as measure of green, is observed for all the samples containing the transparent frits $\mathrm{C}$ and $\mathrm{MD}$, for single firing obtained at $1000{ }^{\circ} \mathrm{C}$ and $1100{ }^{\circ} \mathrm{C}$, detailed in the Table 4 . However when the pigments are enameled with double firing FA, the green chroma is lost and in its place a positive $+a^{*}$ coordinate, with virage

Table 4

Color measurements of starting powders and glazes based on recovered $\mathrm{Cr}_{2} \mathrm{O}_{3}$ (-OR) and using the pure reagent. Chroma $c^{*}$, hue $h^{*}$ and difference of the color calculated as $\Delta E^{*}$.

\begin{tabular}{llllllllll}
\hline Cr source & Frit & $\begin{array}{l}\text { Sample } \\
\text { number }\end{array}$ & $\boldsymbol{L}^{*}$ & $\boldsymbol{a}^{*}$ & $\boldsymbol{b}^{*}$ & $\boldsymbol{c}^{*}$ & $\boldsymbol{h}^{*}$ & $\boldsymbol{\Delta} \boldsymbol{E}^{*}$ \\
\hline $\mathrm{Cr}_{2} \mathrm{O}_{3}$-OR & - & - & 31.18 & -2.03 & 15.59 & 15.72 & 97.42 & 22.20 \\
$\mathrm{Cr}_{2} \mathrm{O}_{3}$ & - & - & 48.05 & -15.92 & 19.53 & 25.20 & 129.18 & \\
$\mathrm{Cr}_{2} \mathrm{O}_{3}$-OR & FC & 1 & 25.83 & -2.35 & 14.68 & 14.86 & 99.10 & 19.47 \\
$\mathrm{Cr}_{2} \mathrm{O}_{3}$ & FC & $1^{\prime}$ & 37.40 & -17.36 & 19.17 & 25.86 & 132.16 & \\
$\mathrm{Cr}_{2} \mathrm{O}_{3}$-OR & MD & 2 & 28.13 & -4.39 & 16.31 & 16.89 & 105.07 & 15.06 \\
$\mathrm{Cr}_{2} \mathrm{O}_{3}$ & MD & $2^{\prime}$ & 34.09 & -17.74 & 19.92 & 26.64 & 131.69 & \\
$\mathrm{Cr}_{2} \mathrm{O}_{3}$-OR & FA & 3 & 25.88 & 6.07 & 27.13 & 27.80 & 77.39 & 10.56 \\
$\mathrm{Cr}_{2} \mathrm{O}_{3}$ & FA & $3^{\prime}$ & 29.70 & 13.46 & 33.64 & 30.2 & 68.20 & \\
\hline
\end{tabular}

Color difference $\Delta \boldsymbol{E}^{*}=\left(\Delta \mathrm{L}^{*^{2}}+\Delta \mathrm{a}^{*^{2}}+\Delta \mathrm{b}^{*^{2}}\right)^{1 / 2}$

Chroma or color saturation: $c^{*}=\left(\mathrm{a}^{* 2}+\mathrm{b}^{* 2}\right)^{1 / 2}$.

Hue or tone of color: $\boldsymbol{h}^{*}=\arctan \left(\mathrm{b}^{*} / \mathrm{a}^{*}\right)+180^{\circ}$ (if the value is negative).

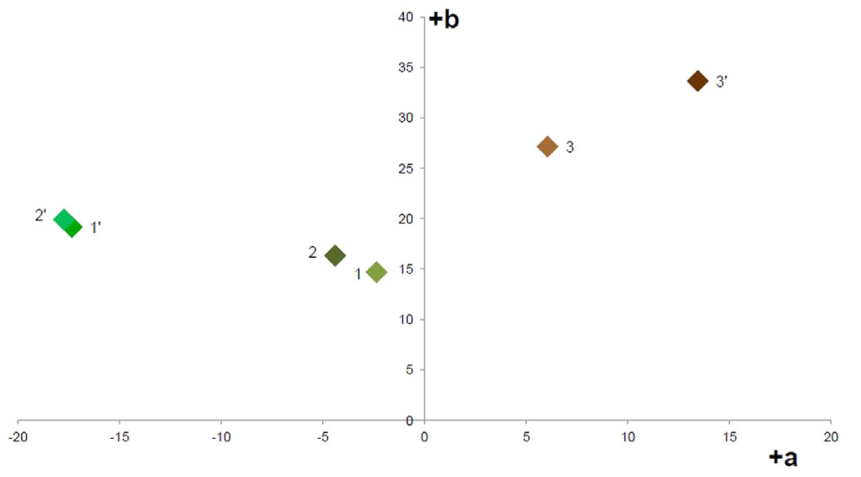

Fig. 8. CIE $L * a * b *$ chroma diagram of $\mathrm{Cr}_{2} \mathrm{O}_{3}$, reference numbers according to Table 4.

towards brown, is produced (Table 4). In comparison with the glazes prepared using pure $\mathrm{Cr}_{2} \mathrm{O}_{3}$ p.a, the green hue of glazes containing $\mathrm{Cr}_{2} \mathrm{O}_{3}$ from OR, labeled 1 and 2 in Table 4, are characterized by less negative $-a^{*}$ values, lower $+b^{*}$ values of yellow (1 and 2), and lower values of lightness.

Regarding the color difference $\Delta E^{*}$, in all cases, it is higher than the established limit $(<0.75)$ by the International Standard ISO 1054516:1999 for Ceramic Tiles. Therefore, the color difference obtained between $\mathrm{Cr}_{2} \mathrm{O}_{3}$ and $\mathrm{Cr}_{2} \mathrm{O}_{3}$-OR is detectable by human vision. $\mathrm{Cr}_{2} \mathrm{O}_{3}-\mathrm{OR}$ could not be used as a substitute for $\mathrm{Cr}_{2} \mathrm{O}_{3}$.

In the $C I E L^{*} C^{*} h *$ model, the green hue is between 120 and 190 degrees. In this study, only samples $1^{\prime}$ and $2^{\prime}$ can be described as green glazes. On the other hand, the lightness $L^{*}$ is very low in all samples. In addition, the calculated chroma or saturation shows that the colors of $\mathrm{Cr}_{2} \mathrm{O}_{3}$-OR are low with respect to the reference and are seen as poor green.

The graph shown in Fig. 8 illustrates the purity of the color. According to the position of each sample in the CIE $L^{*} a * b^{*}$ chroma diagram, the distance from the origin is indicative of the purity of the pigment color. Consequently, in samples 1 and 2 the values closer to the origin, particularly $-a^{*}$ coordinate is indicative of a less pure green shade, as expected. In addition, lower chroma values and lightness suggest darkening of these shades. These effects are due to the other accompanying metal chromophores in the waste, such as $\mathrm{Cu}$ and $\mathrm{Fe}$, although these are present in low amounts. These cations could form brown $\mathrm{CuFe}_{2} \mathrm{O}_{4}$ spinel mixed oxide. Even colorless $\mathrm{Al}(\mathrm{III})$ cation has an effect since it could form $\mathrm{Cr}_{2-\mathrm{x}} \mathrm{Al}_{\mathrm{x}} \mathrm{O}_{3}$ solid solution, belonging to corundum structure; producing a shift from shades of green to red, yielding the well-known red variety of corundum [21]. For this reason, the $\mathrm{Cr}_{2} \mathrm{O}_{3}$-OR is not suitable as a commercial source of $\mathrm{Cr}_{2} \mathrm{O}_{3}$. However this material could be proposed as a potential sustainable alternative of dark green tonality. The chromatic $L^{*}, a^{*}, b^{*}$ parameters are within the chromatic domain of Cr-pigments, enlarging the palette of Cr-green shades, in silicate and aluminate glazes. To assure the invariability of the chemical composition, in order to obtain a pigment with the adequate composition it is necessary to control the waste received. In this way, the chemical analysis and XRD and FTIR measurements of WR and OR should be done before its incorporation to the frits.

On the other hand, in the matrices containing $\mathrm{PbO}$, the positive combination of $+a^{*}$ and $+b^{*}$ values obtained, is responsible for the brown hues. The presence of corrosive $\mathrm{PbO}$ as flux causes the damage of the pigments power. The most remarkable feature is the change of green hues towards a brownish color and the darkening of the glazes. In this way, neither $\mathrm{Cr}_{2} \mathrm{O}_{3}$-OR nor pure $\mathrm{Cr}_{2} \mathrm{O}_{3}$ are stable as green $\mathrm{Cr}$ pigments in this type of frit. Surely the virages detected are associated with the presence of $\mathrm{PbCrO}_{4}$, the toxic pigment formed by the chemical reaction of $\mathrm{PbO}$ and $\mathrm{Cr}_{2} \mathrm{O}_{3}$, in alkaline media [24,25]. 
Table 5

Leaching test of glazes based on Cr-waste.

\begin{tabular}{llll}
\hline $\begin{array}{l}\text { Composition of } \\
\text { samples }\end{array}$ & Mass (g) & $\begin{array}{l}\text { Absorbance mean } \\
\text { values }\end{array}$ & $\begin{array}{l}\mathrm{Cr}(\mathrm{VI}) \text { content } \\
\text { ppm }\left(\mu \mathrm{g} / \mathbf{c m}^{3}\right)\end{array}$ \\
\hline $\mathrm{Cr}_{2} \mathrm{O}_{3}$-OR & 0.5 & 0.054 & 0.007 \\
$\mathrm{Cr}_{2} \mathrm{O}_{3}$-OR + Frit C & 1.4 & 0.063 & 0.009 \\
$\mathrm{Cr}_{2} \mathrm{O}_{3}$-OR + Frit C & 1.4 & 0.090 & 0.012 \\
$\quad$ (duplicate) & & & \\
\hline
\end{tabular}

Experimental conditions: in solution of $\mathrm{pH}=5$ (acetic acid), 24 hs shaking and at $25^{\circ} \mathrm{C}$.

\subsubsection{Leaching tests and toxicity of Cr-enamels based on waste}

The leaching availability was analyzed in order to evaluate the potential environmental risk of using the glazes based on Cr-residue. As well known, the release of $\mathrm{Cr}$ or other toxic elements from a given material depends mainly in their solubility in operative conditions, which is influenced by $\mathrm{pH}$, presence of complex agents, permeability, porosity, contact time, and water/solid ratio [26].

The contamination of the water sources and soil due to solid waste leachate is of concern for health. In the case of chromium, ingestion can cause anemia and stomach cancer. Particularly $\mathrm{Cr}(\mathrm{VI})$ is more dangerous because of its negative environmental impact since it will be segregated to the waste washing waters [21]. Due to the lack of efficient industrial solid waste management, particularly in undeveloped countries, the uncontrolled dumping near towns or cities becomes an environmental problem due to the leachate of various toxic elements and ions. In addition, the leachates affect the water resources close to the dump sites.

If not adequately immobilized in the glaze/ceramic matrix, $\mathrm{Cr}(\mathrm{III})$ residue could be dissolved entering into the environment. Therefore, the evaluation of the removal of chromium from the glazes containing Cr-recovered is relevant.

The leaching behavior of the glazes containing OR are detailed in Table 5. The extraction procedures were described in the experimental section. Several samples of glazes containing recovered $\mathrm{Cr}_{2} \mathrm{O}_{3}$-OR from the chrome plating sludge were collected from the crushed and powdered specimen to provide a representative sampling. The leaching test standard refers to a liquid/dry solid ratio simulating conditions in landfill.

In Argentina, the national law for residual water establishes a maximum limit of $5 \mathrm{mgCr}(\mathrm{VI}) / 1$ of liquids wastes (5.0 ppm of $\mathrm{Cr}(\mathrm{VI})$ ) [27]. As can be seen in Table 5 , all the values regarding $\mu \mathrm{g}$ of chrome/ $\mathrm{cm}^{3}$ solution remain under the limit permitted by regulation. These results suggest that $\mathrm{Cr}(\mathrm{III})$ is stable in the glazes containing $\mathrm{Cr}$ recovered from the waste and that the enameling is a suitable process for the Solidification/Stabilization of this waste. Leaching tests performed on the enamels and $\mathrm{Cr}_{2} \mathrm{O}_{3}$-OR support the proposition that the vitrified hazardous chromium is well stabilized in the glassy matrices. In this way, ceramic technology contributes to inertization of this hazardous waste.

\section{Conclusion}

This study confirmed that the residues from a metallurgical industry, rich in $\mathrm{Cr}$ (III), can be used to synthesize ceramic pigments based on this chromophore. $\mathrm{Cr}_{2} \mathrm{O}_{3}$ was successfully separated from chrome plating waste by two simple steps: first, a washing procedure for extraction of soluble salts; and second, a pyrolisis up to $1000^{\circ} \mathrm{C}$, to decompose the hydrated oxides, eliminate volatiles and organic traces, to render finally the corresponding oxides.

The $\mathrm{Cr}(\mathrm{III})$ oxide is accompanied mainly by $\mathrm{Al}(\mathrm{III})$ oxide, and other minor impurities, compatible with the composition of white ceramic raw materials. In this way, the chemical composition achieved seems to be acceptable for the synthesis of ceramic pigments.

Recovered $\mathrm{Cr}_{2} \mathrm{O}_{3}$ from the optimized waste was used as raw material for the synthesis of glazes for the manufacture of ceramic floor and roof tiles.

Batches containing $5 \mathrm{wt} \%$ were performed and fired according to cycles used for mono and double firing processes. The comparison with the reference tested from pure $\mathrm{Cr}_{2} \mathrm{O}_{3}$ was carried out. The color differences between the glazes prepared from the waste and the reference are noticeable. Therefore, $\mathrm{Cr}_{2} \mathrm{O}_{3}$-OR is not suitable as substitute of commercial $\mathrm{Cr}_{2} \mathrm{O}_{3}$. The presence of small amounts of the other chromophores, such as $\mathrm{Cu}$ (II) and $\mathrm{Fe}(\mathrm{III})$, modifies the purity of the reference shades. Notwithstanding, $\mathrm{Cr}_{2} \mathrm{O}_{3}$-OR could be proposed as a potential sustainable alternative of dark green hues, enlarging the palette of Cr-green shades in single firing glazes; and of brown tonality in the case of overglaze application. The coatings depict a homogeneous microstructure, free of surface defects.

Finally the leaching behavior of the glazes, simulating conditions typical of landfills, was evaluated and the amount of $\mathrm{Cr}(\mathrm{VI})$ lixiviated remains under the limit permitted by regulations.

Leaching tests performed on the enamels and $\mathrm{Cr}_{2} \mathrm{O}_{3}$-OR support the proposition that the vitrified hazardous chromium is well stabilized in the glassy matrices. In this way, ceramic technology contributes to inertization of this hazardous waste, destruction of the organic matter, reduction of the volume of wastes and its transformation into a useful material, with potential for commercial purposes.

\section{Acknowledgements}

This work was supported by SeCAT UNCPBA (Secretaría de Ciencia, Arte y tecnología de la Universidad Nacional del Centro de la provincia de Buenos Aires), and CONICET (Consejo Nacional de Investigaciones Científicas y Técnicas of Argentina). Griselda Xoana Gayo thanks CONICET for her doctoral fellowship.

\section{References}

[1] M. Pelino, Recycling of zinc-hydrometallurgy wastes in glass and glass ceramic materials, Waste Manag. 20 (2000) 561-568.

[2] I. Mármol, P. Ballester, S. Cerro, G. Monrós, J. Morales, L. Sánchez, Use of granite sludge wastes for the production of coloured cement-based mortars, Cem. Concr. Compos. 32 (2010) 617-622.

[3] A. Lavat, M. Trezza, M. Poggi, Characterization of ceramic roof tile wastes as pozzolanic admixture, Waste Manag. 29 (2009) 1666-1674.

[4] M. Garcia-Valles, G. Avila, S. Martinez, R. Terradas, J.M. Nogués, Heavy metal-rich wastes sequester in mineral phases through a glass-ceramic process, Chemosphere 68 (2007) 1946-1953.

[5] D. Esteves, W. Hajjaji, M.P. Seabra, J.A. Labrincha, Use of industrial wastes in the formulation of olivine green pigments, J. Eur. Ceram. Soc. 30 (2010) 3079-3085.

[6] E. Ozel, S. Turan, Ç. Semra, O.N. Ergun, Production of brown and black pigments by using flotation waste from copper slag, Waste Manag. Res. 24 (2006) 125-133.

[7] G. Costa, V.P. Della, M.J. Ribeiro, A.P.N. Oliveira, G. Monrós, J.A. Labrincha, Synthesis of black ceramic pigments from secondary raw materials, Dyes Pigments 77 (2008) 137-144.

[8] C. Sikalidis, V. Zaspalis, Utilization of $\mathrm{Mn}-\mathrm{Fe}$ solid wastes from electrolytic $\mathrm{MnO}_{2}$ production in the manufacture of ceramic building products, Constr. Build. Mater. 21 (2007) 1061-1068.

[9] B. Ebin, M. Petranikova, B.-M. Steenari, C. Ekberg, Production of zinc and manganese oxide particles by pyrolysis of alkaline and $\mathrm{Zn}-\mathrm{C}$ battery waste, Waste Manag. 51 (2016) 157-167.

[10] A. Cotton, G. Wilkinson, Advanced Inorganic Chemistry, 3rd ed., Wiley, USA, 1962.

[11] F.J. Berry, N. Costantini, L.E. Smart, Synthesis of chromium-containing pigments from chromium recovered from leather waste, Waste Manag. 22 (2002) 761-772.

[12] G. Costa, M.J. Ribeiro, T. Trindade, J.A. Labrincha, Development of waste-based ceramic pigments, Bol. Soc. Esp. Ceram. Vidr. 46 (2007) 7-13.

[13] P.E. Werner, FORTRAN program for least-squares refinement of crystal structure cell dimensions, Ark. Kemi. 31 (1969) 513-516.

[14] USEPA. Method 1310B: extraction procedure (EP) toxicity test method and structural integrity test. United States Environmental Protection Agency Publications, Revision 2, Washington, November 2004.

[15] IRAM Standard 38-404 Part II. Toxicology. Toxic or undesirable elements: Method for the determination of hexavalent chromium by the spectrophotometric technique with diphenylcarbazide, 1989.

[16] J.M. Magalhães, J.E. Silva, F.P. Castro, J.A. Labrincha, Physical and chemical characterisation of metal finishing industrial wastes, J. Environ. Manag. 75 (2005) 157-166.

[17] Ch.J. Pouchert, The Aldrich Library of FT-IR Spectra: Vol 1 \& 2, Aldrich Chemical Company, inc., 1985. 
[18] H.R. Mahmoud, Highly dispersed $\mathrm{Cr}_{2} \mathrm{O}_{3}-\mathrm{ZrO}_{2}$ binary oxide nanomaterials as novel catalysts for ethanol conversion, J. Mol. Catal. A-Chem. 392 (2014) 216-222.

[19] P. Gibot, L. Vidal, Original synthesis of chromium (III) oxide nanoparticles, J. Eur. Ceram. Soc. 30 (2010) 911-915.

[20] T. Arii, Y. Sawada, K. Lizumi, K. Kudaka, S. Seki, TG-DTA-MS of chromium(III) formate, Thermochim. Acta 352-353 (2000) 53-60.

[21] R. Muñoz, N. Masó, B. Julián, F. Márquez, H. Beltrán, P. Escribano, E. Cordoncillo, Environmental study of $\mathrm{Cr}_{2} \mathrm{O}_{3}-\mathrm{Al}_{2} \mathrm{O}_{3}$ green ceramic pigment synthesis, J. Eur. Ceram. Soc. 24 (2004) 2087-2094.

[22] A.E. Lavat, C.C. Wagner, J.E. Tasca, Interaction of Co-ZnO pigments with ceramic frits: a combined study by XRD, FTIR and UV-visible, Ceram. Int. 34 (2008) $2147-2153$
[23] R.A. Eppler, Selecting ceramic pigments, Ceram. Bull. 66 (1987) 1600-1604.

[24] T.S. Lyubenova, Non-conventional synthesis and characterization of ceramic pigments based on chromium (Doctoral Thesis), Castellón de la Plana: Universidad Jaume I, 2009.

[25] R. Hevia, N. Centritto, P. A Novaes de Oliveira, A.M. Bernardín, A. Durán, Introduction to Ceramic Glazes, Ed. Alicia Durán. CYTED, 2002.

[26] H.A. van der Sloot, Readily accessible data and an integrated approach is needed for evaluating waste treatment options and preparation of materials for beneficial use, Waste Manag. 24 (2004) 751-752.

[27] Decree 2020/2007 of 2214/06. Law Official Bulletin of the Ciudad Autónoma de Buenos Aires No. 2831, Argentina, 2007. 